\title{
Corrigendum: Lactate Metabolism and Satellite Cell Fate
}

\author{
Minas Nalbandian ${ }^{1 *}$, Zsolt Radak ${ }^{2}$ and Masaki Takeda ${ }^{3 *}$ \\ ${ }^{1}$ Department of Clinical Application, Center for iPS Cell Research and Application (CiRA), Kyoto University, Kyoto, Japan, \\ ${ }^{2}$ Research Center of Molecular Exercise Science, University of Physical Education, Budapest, Hungary, ${ }^{3}$ Graduate School of \\ Sports and Health Science, Doshisha University, Kyoto, Japan
}

Keywords: lactate, muscle stem cell, metabolism, skeletal muscle, muscle regeneration

\section{A Corrigendum on}

\section{OPEN ACCESS}

Edited and reviewed by: Luc Pellerin,

University of Poitiers, France

*Correspondence:

Minas Nalbandian

hm.nalbandian@cira.kyoto-u.ac.jp Masaki Takeda

mtakeda@mail.doshisha.ac.jp

Specialty section:

This article was submitted to Striated Muscle Physiology, a section of the journal Frontiers in Physiology

Received: 17 November 2021 Accepted: 30 November 2021 Published: 15 February 2022

Citation: Nalbandian M, Radak Z and Takeda M (2022) Corrigendum: Lactate Metabolism and Satellite Cell Fate.

Front. Physiol. 12:817264. doi: 10.3389/fphys.2021.817264

\section{Lactate Metabolism and Satellite Cell Fate}

by Nalbandian, M., Radak, Z., and Takeda, M. (2020). Front. Physiol. 11:610983. doi: $10.3389 /$ fphys.2020.610983

In the original article, there was an error. We state that LDHA isoform converts lactate to pyruvate and that LDHB converts pyruvate into lactate. The current evidence suggests that LDHA and LDHB both can favor the lactate to pyruvate conversion in any direction.

A correction has been made to "LACTATE AS A KEY METABOLITE IN THE CONTROL OF CELL SIGNALING," Paragraph 1: "Lactate is a metabolite produced from pyruvate by lactate dehydrogenase ( $\mathrm{LDH}$ ), with the LDH isoform A (LDHA) facilitating the pyruvate-to-lactate conversion in cells with high glycolytic rates, and the LDH isoform B (LDHB) facilitating the lactateto-pyruvate conversion in highly oxidative cells. When the cytoplasmic lactate concentration is elevated, lactate can be co-transported with one $H+$ ion outside the cell by facilitated diffusion via monocarboxylate transporters (MCTs; Halestrap and Wilson, 2012; Kitaoka et al., 2012; Halestrap, 2013; Perez-Escuredo et al., 2016). MCT1 and MCT4 are MCT isoforms expressed in skeletal muscle (Bonen, 2001). MCT1, which has a relatively low Km (3.5-10 mM; Halestrap, 2012), is the predominant isoform in oxidative skeletal muscle fibers and considered responsible for lactate uptake (Mccullagh et al., 1997; Juel and Halestrap, 1999; Pilegaard et al., 1999; Halestrap, 2012; Chatel et al., 2017). On the other hand, MCT4, which has a much higher Km (22-28 mM; Halestrap, 2012), is the isoform predominantly expressed in glycolytic skeletal muscle fibers and considered responsible for lactate release (Dimmer et al., 2000; Fox et al., 2000; Bisetto et al., 2019). Extracellular lactate can travel through the blood stream to many cells, serving as an important energy source for several tissues and organs such as the brain (van Hall et al., 2009; Mosienko et al., 2015), liver, and skeletal muscle (Hui et al., 2017; Brooks, 2020). 
Given lactate's ability to travel between cells, tissues, and organs, recently it was proposed to be a signaling molecule (Nalbandian and Takeda, 2016; Brooks, 2020).”

\section{REFERENCES}

Bisetto, S., Wright, M. C., Nowak, R. A., Lepore, A. C., Khurana, T. S., Loro, E., et al. (2019). New insights into the lactate shuttle: role of MCT4 in the modulation of the exercise capacity. iScience 22, 507-518. doi: 10.1016/j.isci.2019.11.041

Bonen, A. (2001). The expression of lactate transporters (MCT1 and MCT4) in heart and muscle. Eur. J. Appl. Physiol. 86, 6-11. doi: 10.1007/s004210100516

Brooks, G. A. (2020). Lactate as a fulcrum of metabolism. Redox Biol. 35:101454. doi: 10.1016/j.redox.2020.101454

Chatel, B., Bendahan, D., Hourde, C., Pellerin, L., Lengacher, S., Magistretti, P., et al. (2017). Role of MCT1 and CAII in skeletal muscle pH homeostasis, energetics, and function: in vivo insights from MCT1 haploinsufficient mice. FASEB J. 31, 2562-2575. doi: 10.1096/fj.201601259R

Dimmer, K. -S., Friedrich, B., Lang, F., Deitmer, J. W., and Bröer, S. (2000). The low-affinity monocarboxylate transporter MCT4 is adapted to the export of lactate in highly glycolytic cells. Biochem. J. 350, 219-227. doi: $10.1042 / \mathrm{bj} 3500219$

Fox, J. E. M., Meredith, D., and Halestrap, A. P. (2000). Characterisation of human monocarboxylate transporter 4 substantiates its role in lactic acid efflux from skeletal muscle. J. Physiol. 529, 285-293. doi: 10.1111/j.1469-7793.2000.00285.x

Halestrap, A. P. (2012). The monocarboxylate transporter family-structure and functional characterization. IUBMB Life 64, 1-9. doi: 10.1002/iub.573

Halestrap, A. P. (2013). The SLC16 gene family - structure, role and regulation in health and disease. Mol. Asp. Med. 34, 337-349. doi: $10.1016 /$ j.mam.2012.05.003

Halestrap, A. P., and Wilson, M. C. (2012). The monocarboxylate transporter family-role and regulation. IUBMB Life 64, 109-119. doi: 10.1002/iub.572

Hui, S., Ghergurovich, J. M., Morscher, R. J., Jang, C., Teng, X., Lu, W., et al. (2017). Glucose feeds the TCA cycle via circulating lactate. Nature 551, 115-118. doi: $10.1038 /$ nature24057

Juel, C., and Halestrap, A. P. (1999). Lactate transport in skeletal muscle role and regulation of the monocarboxylate transporter. J. Physiol. 517, 633-642.

Kitaoka, Y., Hoshino, D., and Hatta, H. (2012). Monocarboxylate transporter and lactate metabolism. J. Phys. Fit. Sports Med. 1, 247-252. doi: 10.7600/jpfsm.1.247
The authors apologize for this error and state that this does not change the scientific conclusions of the article in any way. The original article has been updated.

Mccullagh, K. J., Poole, R. C., Halestrap, A. P., Tipton, K. F., O’brien, M., and Bonen, A. (1997). Chronic electrical stimulation increases MCT1 and lactate uptake in red and white skeletal muscle. Am. J. Physiol. Endocrinol. Metab. 273, E239-E246. doi: 10.1152/ajpendo.1997.273.2.E239

Mosienko, V., Teschemacher, A. G., and Kasparov, S. (2015). Is L-lactate a novel signaling molecule in the brain? J. Cereb. Blood Flow Metab. 35, 1069-1075. doi: $10.1038 /$ jcbfm.2015.77

Nalbandian, M., and Takeda, M. (2016). Lactate as a signaling molecule that regulates exercise-induced adaptations. Biology 5:38. doi: 10.3390/biology5040038

Perez-Escuredo, J., Van Hee, V. F., Sboarina, M., Falces, J., Payen, V. L., Pellerin, L., et al. (2016). Monocarboxylate transporters in the brain and in cancer. Biochim. Biophys. Acta 1863, 2481-2497. doi: 10.1016/j.bbamcr.2016.03.013

Pilegaard, H., Terzis, G., Halestrap, A., and Juel, C. (1999). Distribution of the lactate/H+ transporter isoforms MCT1 and MCT4 in human skeletal muscle. Am. J. Physiol. Endocrinol. Metab. 276, E843-E848. doi: 10.1152/ajpendo.1999.276.5.E843

van Hall, G., Stromstad, M., Rasmussen, P., Jans, O., Zaar, M., Gam, C., et al. (2009). Blood lactate is an important energy source for the human brain. J. Cereb. Blood Flow Metab. 29, 1121-1129. doi: 10.1038/jcbfm.2009.35

Publisher's Note: All claims expressed in this article are solely those of the authors and do not necessarily represent those of their affiliated organizations, or those of the publisher, the editors and the reviewers. Any product that may be evaluated in this article, or claim that may be made by its manufacturer, is not guaranteed or endorsed by the publisher.

Copyright (c) 2022 Nalbandian, Radak and Takeda. This is an open-access article distributed under the terms of the Creative Commons Attribution License (CC BY). The use, distribution or reproduction in other forums is permitted, provided the original author(s) and the copyright owner(s) are credited and that the original publication in this journal is cited, in accordance with accepted academic practice. No use, distribution or reproduction is permitted which does not comply with these terms. 